\title{
Retraction Note: Solder Selection for Reflowing Large Ceramic Substrates During PCB Assembly
}

\author{
Prashant Reddy Gangidi · Noy Souriyasak
}

Published online: 3 September 2018

(C) ASM International 2018

\section{Retraction Note to:}

J Fail. Anal. and Preven. (2017) 17:699-705

https://doi.org/10.1007/s11668-017-0296-1

This article has been retracted by the corresponding author as he did not have permission to publish the data. The editor has been unable to contact Noy Souriyasak regarding this retraction. The scientific content has been removed for legal reasons.

The retracted article can be found online at https://doi.org/10.1007/ s11668-017-0296-1.

P. R. Gangidi ( $\square)$

Quality and Reliability Engineering, FormFactor Inc, Livermore,

CA, USA

e-mail: prashantrg.bits@gmail.com

N. Souriyasak

Process Engineering, FormFactor Inc, Livermore, CA, USA

e-mail: n.souriyasak@formfactor.com 